\title{
Project Contingent Repudiation Risk in the Model of North-South Lending.
}

\author{
Constantin T. Gurdgiev \\ Department of Economics \\ Trinity College, Dublin \\ Department of Economics, \\ National University of Ireland, Maynooth \\ Open Republic Institute, Dublin.
}

gurdgiec@tcd.ie

$1^{\text {st }}$ Draft: April 2002.

$2^{\text {nd }}$ Draft: August 2002

\begin{abstract}
.
Present research proposes the extension of the Gertler-Rogoff-Lane model of international lending under the risk of repudiation with moral hazard to encompass the possibility of the project contingency in the repudiation risk itself. By linking the level of repudiation risk to the size of the project we show that investment projects undertaken can be biased in a direction favouring larger projects. Alternatively, we show that smaller investors are required in the marketplace, under certain conditions, to provide greater guarantees or higher collateral in order to obtain funds needed for investment.
\end{abstract}




\section{Introduction.}

In recent years, the role of risk and in particular repudiation risk as a determinant of investment decisions and capital flows has been highlighted by a plethora of models. At the same time, traditional models of repudiation risk have invariably avoided endogenising the risk-project relationship outside the general framework of the moral hazard and agency problems. Yet, with development of democratic institutions and the opening of national boundaries to trade and capital flows, information flows have come to the forefront of the real investment projects assessment with respect to both the inherent risk involved and the role that the nature of the project plays within the constraints of such institutions on the level of overall risk.

While the former aspect of the repudiation risk is covered extensively in the existing literature, the latter remains largely unexplored. Yet as the result of these different facets of the same phenomena, both the inherent risk of the investments and the repudiation risk in particular are often endogenous to the environment of the project. Another aspect worth considering is the relationship between the project characteristics, such as size, and the overall availability of information. In the societies with developed democratic institutions, such as courts, media and political campaigning, larger projects enjoy greater public visibility and electoral scrutiny. Thus such projects may be naturally associated with the lower repudiation risk. On the other hand, in the societies with severe degrees of market distortions and corruption, large projects may be associated with government involvement and thus may be linked to a higher degree of repudiation risk. In what follows, we term these effects project-contingent nature of repudiation risk and for the sake of brevity deal with the first type of relationship between the nature of the project and the inherent level of risk involved.

The majority of repudiation risk literature focuses on the open economy side of the macroeconomic models, while the larger share of moral hazard models is concerned with the closed economies. For example, the seminal paper by Gertler and Rogoff develops a 
model of investment under uncertainty in the presence of moral hazard that ignores the possibility of repudiation risk. As such, this model, according to authors' admission, cannot be used to distinguish investment flows between two states within the US and the two sovereign countries. Lane $(1998,1999)$ extension introducing repudiation risk moves this model into the open economy macroeconomics, while leaving the consideration of project-specificity of risk not addressed. Similarly, an important paper by Holmstrom and Tirole (1998) focuses on the closed economy aspect of agency risk without providing an analysis of the repudiation risk, or the link between the nature of the project and the repudiation risk.

Furthermore, traditional literature on repudiation risk and investment lending rarely deals with the implications of the project nature or size linkages to the overall riskiness of the project. In so far as repudiation risk is related to the limited liability and bankruptcy liquidation laws, this implies that most theoretical models of lending under moral hazard lead to a conclusion that costs of such risk are either evenly born by all entrepreneurs, or benefit small investors in excess of the large ones. However, as shown by many studies, see for example Groop et al (1996) and Berkowitz and White (2002), empirically such costs act to redistribute credit away from small entrepreneurs in favour of the larger projects. This empirical contradiction to theoretical models of lending under moral hazard risk appears to be unresolved in the modern literature.

Current study is designed to fill these gaps by extending the Gertler-Rogoff-Lane framework to include consideration of the project contingent repudiation risk. In the following we assume that the importance of repudiation risk in investment decisions rests in part on the differences amongst various projects. For simplicity, we assume that this endogeneity of repudiation risk is linked to a specific characteristic of the project, namely its size. However, the model presented below can be easily extended to cover many contingencies within the realm of the project environment's description. 


\section{Part 1. Model.}

There are two types of risk-neutral agents, each living two periods $t$ and $t+1$ :

entrepreneurs and lenders. Lenders are interested in maximising the expected rate of repayment on the project, while entrepreneurs maximise their expected utility over the choices of consumption and investment (assumed to be proportional to the capital outlay for the project), subject to budget constraint. Life-time utility is given by:

$E_{t} U\left(C_{t}, C_{t+1}, k\right)=\log C_{t}+\beta E_{t} \log C_{t+1}-a \log k_{t}$

where in general $U_{t}^{C}>0, U_{t+1}^{C}>0, U_{t}^{C C}, U_{t+1}^{C C}<0$ and $U_{t}^{k} \leq 0, U_{t}^{k k}>0$.

The income available to entrepreneurs arises from two sources. Original, period $t$ endowment of wealth, $W$, can be invested in risky project with state contingent payoffs described below, and the risk free asset, $B_{t}$, yielding the gross rate of return, $R$. Risky investment technology is given as follows. At date $t$ entrepreneur uses her own funds, $W-C_{t}$, together with the borrowed amount of $b$ to finance capital formation in the amount of $k$. This capital is then applied to the risky investment project and entrepreneur chooses the level of effort to be applied to the project. The residual funds are automatically deposited into bond holdings.

The project yields at date $t+1$ a return $\theta_{G}$ with probability $\pi(k)$ corresponding to the 'good' state of nature, or a return $\theta_{B}$ with probability $1-\pi(k)$ corresponding to the 'bad' state of nature. We assume that $0 \leq \theta_{B}<<\theta_{G}$. Level of effort (capital outlay to the project) under the possibility of investing the borrowed funds in the risk-free asset is private information available to the entrepreneur but not to an investor. At date $t$ upon borrowing funds for investment, entrepreneur commits to repay state-contingent rate of return $Z_{G} \geq Z_{B}$. However, investor faces an additional risk of default due to limited liability (repudiation). After realisation of the project, investors may expropriate only a share of final output. This share is project-size-contingent, so that $\alpha(k) \theta_{i} \geq Z_{i} \quad i=G, B$ 
We shall consider only one case: $\alpha^{\prime}(k)>0$, corresponding to the situations in which repudiation risk is decreasing (so that repayment share is increasing) in the size of a project. In a democratic society with developed media and socio-political checks and balances on corporate and public bureaucracy, high profile (large $k$ ) investment projects are associated with higher degree of visibility. The resulting reduction of information costs makes larger projects cheaper to monitor than smaller ones. In addition, with high degree of public exposure, such projects are less subject to corruption (media exposure in democratic setting increases cost of corruption) and therefore are associated with lower repudiation risk than smaller, less visible ones. This situation can warrant the aforementioned link between the size of the project and the repudiation risk involved. As was mentioned in the introduction, in case of severe corruption problems at the top of the government apparatus, we can specify the opposite direction of the relationship between the project size and repudiation risk involved. Such extension of the model would require reversing the sign of $\alpha^{\prime}(k)$ to $\alpha^{\prime}(k)<0$.

Given the expected rate of return to the risky investment project, we specify the intertemporal budget constraint as:

$C_{t}+\frac{C_{t+1}}{R} \leq \frac{\pi(k)}{R}(\theta-\mathrm{Z})+\frac{\left(\theta_{B}-\mathrm{Z}_{B}\right)}{R}+W+b-k$

Denote by $Z=Z_{G}-Z_{B}$ and $\theta=\theta_{G}-\theta_{B}$. To control for the presence of moral hazard problem in terms of investment project choice, we impose the standard incentive compatibility constraint according to which risky projects must yield at least the same rate of return as risk-free bonds:

$\pi^{\prime}(k)(\theta-Z) \geq R$

We further assume that neither future income, nor the expected repudiation funds can be leveraged in the debt markets, so that

$W+b-k-B_{t}-C_{t} \geq 0$

Furthermore, investors must be guaranteed a repayment level at least in the amount of the opportunity cost of risky investment, i.e. $R$ :

$\pi(k) Z+Z_{B} \geq R b$ 
We are now ready to postulate the problems faced by entrepreneur who chooses consumption over two periods, capital investment, debt level, and the level of the statecontingent repayment to offer so as to:

$\max _{\left\{C_{t}, C_{t+1}, k, b, Z_{G}, Z_{B}\right\}} E_{t} U\left(C_{t}, C_{t+1}, k_{t}\right)$

subject to (1)-(6). Denote by $\phi_{i}, \lambda, \mu, \gamma, \psi$ the multipliers on constraints (2)-(6)

respectively. Then the first order conditions for the general problem are given by:

$$
\begin{aligned}
& U_{t}^{C}-R \beta U_{t+1}^{C}=\gamma=\frac{1}{C_{t}}-\frac{R \beta}{C_{t+1}} \\
& R \beta U_{t+1}^{C}=\lambda=\frac{R \beta}{C_{t+1}}>0 \\
& U_{t}^{k}+\lambda\left[\frac{\pi^{\prime}}{R}(\theta-Z)-1\right]+\psi \pi^{\prime} Z+\mu \pi^{\prime \prime}(\theta-Z)+\alpha^{\prime}\left(\phi_{G} \theta_{G+}+\phi_{B} \theta_{B}\right)-\gamma= \\
& \frac{a}{k_{t}} \lambda\left[\frac{\pi^{\prime}}{R}(\theta-Z)-1\right]+\psi \pi^{\prime} Z+\mu \pi^{\prime \prime}(\theta-Z)+\alpha^{\prime}\left(\phi_{G} \theta_{G+}+\phi_{B} \theta_{B}\right)-\gamma=0 \\
& \lambda+\gamma=\psi R \\
& \pi\left[\psi-\frac{\lambda}{R}\right]-\pi^{\prime} \mu=\phi_{G} \\
& (1-\pi)\left[\psi-\frac{\lambda}{R}\right]+\pi^{\prime} \mu=\phi_{B}
\end{aligned}
$$

From (7a) it is clear that we have two cases to consider:

Case 1: $\quad R \beta C_{t}=C_{t+1} \Leftrightarrow U_{t}^{C}=R \beta U_{t+1}^{C}$ which implies that $\gamma=0$ with (5) satisfied at inequality. This is a case when borrowers will hold non-zero level of bonds and collateral reserve, so that moral hazard applies.

As shown below the resulting optimal level of capital allocation is below the full information first-best solution in Gertler-Rogoff-Lane.

Case 2: $\quad U_{t}^{C}>R \beta U_{t+1}^{C}$ which implies that $\gamma>0$ and (5) is satisfied at equality. This is a case when borrowers will hold no bonds and colateral, so that moral hazard does not constrain the optimal level of capital available to borrowers. Repudiation risk alone matters. As shown below the resulting optimal capital allocation is determined by its effect on repudiation risk. 


\section{Part 2. Case-Specific Solutions.}

\subsection{Case 1: Moral Hazard in Absence of Effective Repudiation Risk.}

Consider Case 1 . Since $\gamma=0$, then the optimal solution to the problem is given by the following equations:

$$
\begin{aligned}
& \pi(k) Z+Z_{B} \geq R b \\
& \text { MR curve } \quad b=C_{t}+k_{t}-W+B_{t} \\
& B_{t}>0 \\
& \text { IC curve } \quad \pi^{\prime}(k)(\theta-Z)>R \\
& \text { ZZ curve } \\
& \alpha(k) \theta>\mathrm{Z} \\
& \alpha(k) \theta_{i}>Z_{i} \quad \forall i=G, B \\
& -U_{t}^{k}=\frac{U_{t}^{C}}{R}\left[\pi^{\prime}(k) \theta-R\right] \\
& k_{1}^{*}=\frac{a C_{t} R}{\pi^{\prime} \theta-R}
\end{aligned}
$$

Comparing intercept $I C$ with $k_{1}^{*}$ level, $k_{1}^{*}<k_{0}^{I C}$. The reason for this is that under the assumptions of Case 1 moral hazard applies and borrowers have to set aside a certain amount of reserves in form of bonds to supply collateral for the loans. This limits the level of capital investment that can be undertaken. However, since net return to borrowers after repayment of the loan is higher than the risk-free rate of return, $I C$ constraint does not bind at the optimum. Hence $k_{1}^{*}>\tilde{k}$, where $\tilde{k}$ denotes the solution to standard G-R-L problem without repudiation risk but with moral hazard. In presence of collateral, borrowers can guarantee higher repayment rate $Z_{1}^{*}>\tilde{Z}$ than in case of G-R-L. Thus, lenders are compensated for the added risk by obtaining the expected returns in excess of risk-free rate of return. The repudiation risk does not matter in this case because it is effectively offset by the bond holdings, which can be repudiated under the assumptions of (2), (3) and (5). Figure 1 below shows these results. 
Figure 1. Equilibrium Levels of Capital Investment and Repayment Pledge. Benchmark Case of No Repudiation Risk.

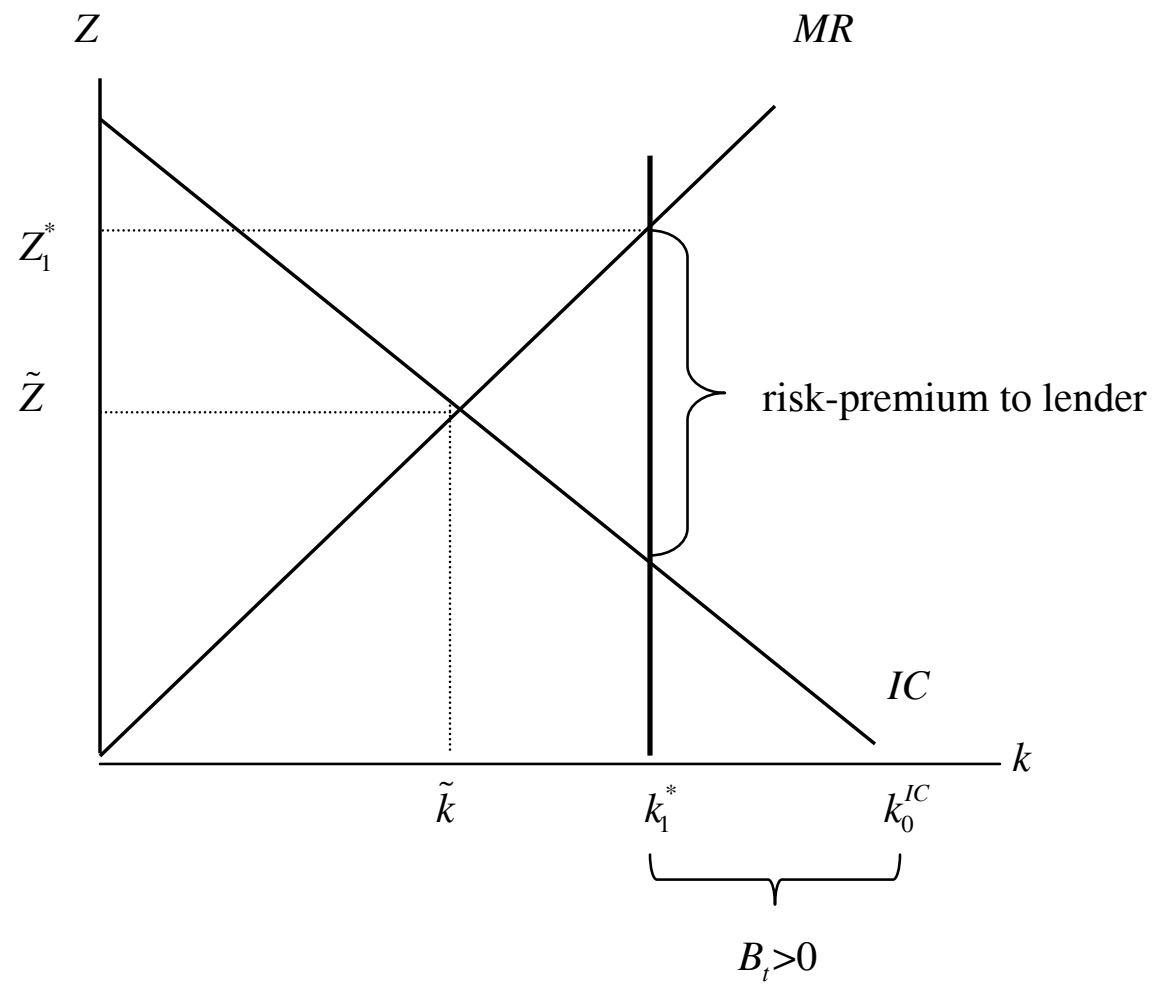

Note that in this case welfare analysis conducted in Gertler (1992) fully applies. Thus increase in wealth endowment of entrepreneurs will shift both $I C$ and $M R$ curves rightward thereby increasing the credit availability. Alternatively increase in personal wealth will reduce the risk-premium required by the lenders.

\subsection{Case 2: Moral Hazard in Presence of Repudiation Risk.}

Next we consider Case 2. In general, assumptions for this case imply that $\gamma>0$, so that outside the bond holdings collateral reserves are zero and constraint (5) holds at equality. It is straightforward to show that equalities in constraints (3) and (6) will follow as well. Finally, simplifying (7c) we can summarise the main equations of the model as follows: 


$$
\begin{array}{cl}
\text { MR curve } & \pi(k) Z+Z_{B}=R b \\
& b=C_{t}+k_{t}-W \\
\text { IC curve } & \pi^{\prime}(k)(\theta-Z) \geq R \\
& \alpha(k) \theta \geq Z \\
\text { ZZ curve } & \alpha(k) \theta_{i} \geq Z_{i} \quad \forall i=G, B
\end{array}
$$

E-level

$$
-U_{t}^{k}=\pi^{\prime}(k)\left\{\beta U_{t+1}^{C}(\theta-Z)+\frac{U_{t}^{C}}{R} Z\right\}+\mu \pi^{\prime \prime}(\theta-Z)-U_{t}^{C}+\alpha^{\prime}(k)\left[\phi_{G} \theta_{G}+\phi_{B} \theta_{B}\right]
$$

As in G-R-L we can consider two cases of application of repudiation risk.

Case 2.A.: $\quad$ repudiation risk does not bind in 'good' state, i.e. $\phi_{G}=0$

Case 2.B.: $\quad$ repudiation risk does bind in 'good' state, i.e. $\phi_{G}>0$

\subsubsection{Case 2.1: Repudiation Risk in 'Bad' State Alone}

First suppose repudiation risk constraint does not bind in case of 'good' state realisation. This implies that $\alpha(k) \theta_{G}>\mathrm{Z}_{G}$ and therefore, $\phi_{B}>0$ unambiguously. The governing equations are:

$$
\begin{array}{ll}
\text { MR curve } & \pi(k) Z+\alpha(k) \theta_{B}=R\left(k_{t}+C_{t}-W\right) \\
\text { IC curve } & \pi^{\prime}(k)(\theta-Z)=R \\
\text { ZZ curve } & \alpha(k) \theta>Z \\
& \frac{a}{k_{i}^{*}}=A\left[Z \pi^{\prime}+\frac{\pi \pi^{\prime \prime}}{\pi^{\prime}}(\theta-Z)+\alpha^{\prime} \theta_{B}\right]-\frac{1}{C_{t}}+\beta \frac{\pi^{\prime} \theta}{C_{t+1}} \\
\text { E-level } & A=\frac{1}{R C_{t}}-\frac{\beta}{C_{t+1}}
\end{array}
$$

As before, $M R$ curve slopes up in $(k, Z)$ space, however, equation (10a) gives a flatter slope than corresponding equation in Case 1, since now repudiation constraint does not bind in 'good' state. In addition, $M R$ has non-zero intercept at $k_{0}^{M R}$. 
Relative to $Z Z$ curve, $M R$ is steeper or flatter whenever $\alpha^{\prime}(k) \geq,<\frac{R-Z \pi^{\prime}(k)}{\pi(k) \theta+Z_{B}}$. The interpretation for this cut-off point on repudiation coefficient is that when capital stock has strong effect on repudiation risk reduction, $\alpha^{\prime}(k) \geq \frac{R-Z \pi^{\prime}(k)}{\pi(k) \theta+Z_{B}}$, repudiation risk will matter less than moral hazard in determining borrowing opportunities available to agents. Marginal effect of decreasing repudiation risk being strong, lenders will now accept lower risk premium. The fall in incentives for borrowers to raid loan funds and deposit these funds into bonds (moral hazard) increases slower with raising capital, in this case, than their ability to repay the lenders. Hence, lenders are willing to lend more in this case than in case of weaker effect of capital level on repudiation risk. These differences are captured by relative positions of $Z Z$ (strong) and $Z Z$ (weak) curves vis-à-vis $M R$ curve in Figure 2.

Figure 2. Equilibrium Levels of Capital Investment and Repayment Pledge. Case of Repudiation Risk Accruing to Bad State.

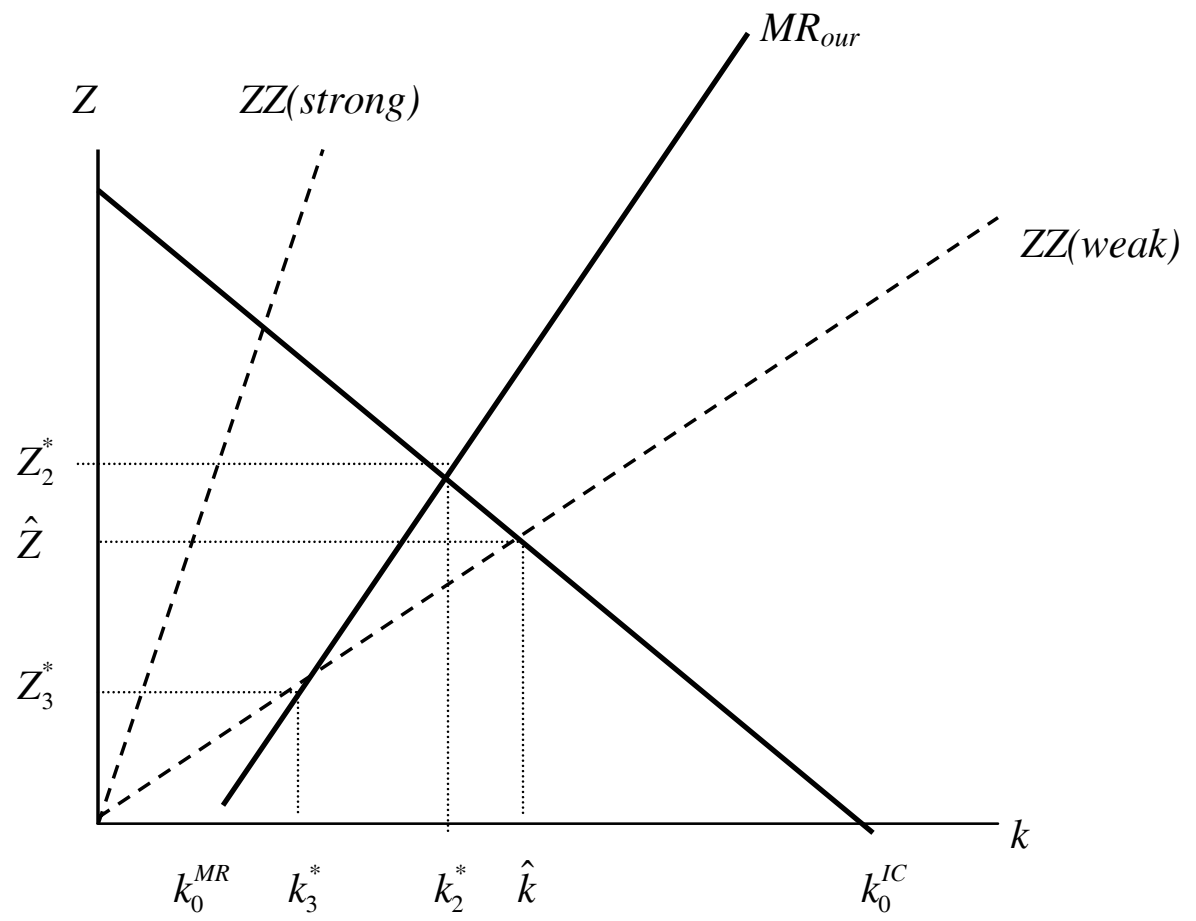


With weak effect of capital stock on repudiation risk, however, the lenders are not willing to supply capital in excess of the optimal amount determined by the repudiation risk constraint (MR curve) and lender repayment constraint ( $Z Z$ curve). Hence, solutions to this problem for lower effect case are given by:

$\left(k_{3}^{*}, Z_{3}^{*}\right) \in\left\{(k, Z) \in R_{+}^{2}: k_{0}^{M R} \leq k<k_{2}^{*} \wedge 0 \leq Z_{3}^{*}<Z_{2}^{*}\right\}$.

While in the benchmark case the optimal solution is: $(\hat{k}, \hat{Z})$

Thus there exist an optimal level of repudiation risk, determined by point $\left(k_{2}^{*}, Z_{2}^{*}\right)$ at which lenders are willing to supply maximum level of loans in exchange for being reimbursed by the borrowers with the proceeds from investment project. Borrowers will hold zero bonds and will invest all borrowed funds into risky project. They will ex-ante commit to repay exactly $Z_{2}^{*}=\alpha^{*}(k) \theta$ in expected repayments which corresponds to the share that can be seized by lenders from the borrowers.

Note that the distance between $\hat{Z}$ and $Z_{2}^{*}$ is the exact measure of the repudiation risk premium required by the investors in excess of entrepreneur's pledge of $Z_{2}^{*}$ that would serve to secure the highest possible level of capital raised by entrepreneur in the case where repudiation risk is weakly responsive to the size of investment.

Comparing these results with Case 1 , we have that $k_{2}^{*}<k_{1}^{*}$, and $k_{2}^{*}<\tilde{k}$. Hence, as expected in presence of effective moral hazard and repudiation risk (at least in one state) we achieve lower capital levels than in case where repudiation risk is effectively nonbinding. 


\subsubsection{Case 2.2: Repudiation Risk in Both States.}

Under the assumption that $\phi_{G}>0$, repudiation constraint binds in both 'good' and 'bad' states of nature. This implies that the solution to the problem is determined by the following system of equations:

MR curve $\quad \pi(k) Z+\alpha(k) \theta_{B}=R\left(k_{t}+C_{t}-W\right)$

IC curve $\quad \pi^{\prime}(k)(1-\alpha(k)) \theta=R$

ZZ curve $\quad \alpha(k) \theta=\mathrm{Z}$

Equilibrium level $\quad \pi(k) \alpha(k) \theta+\alpha(k) \theta_{B}=\alpha(k) E[\theta]=R\left(k_{t}+C_{t}-W\right)$

Once again, $Z Z$ curve relative to $M R$ is steeper or flatter depending on whether the effect of capital level on repudiation risk is strong $\left(\alpha(k) \geq \frac{R\left(k+C_{t}-W\right)}{E[\theta]}\right)$ or weak. This is the same threshold value for the effect strength as in Case 2.1 above.

However, comparing the point given by intersection of $I C$ and $M R$ curves (maximal solution to problem in case 2.1 given by $\left.\left(k_{2}^{*}, Z_{2}^{*}\right)\right)$, with the solution to $E$-level equation (11d) above, it can be shown that $k_{4}^{*}<k_{2}^{*}$ so that in case of strong effect of repudiation risk the resulting level of capital expenditure will be below the levels achieved in similar case under the assumption that repudiation risk binds in 'bad' state alone. The result is expected. Relative to case 2.1 in present set up investors are concerned with repudiation risk in both states. This in return warrants higher demanded repayment pledge and implies lower capital expenditure.

Solutions to this case are given in Figure 3. It is important to note that in this case investors are willing to accept lower repayment, as repudiation risk is falling in the size of the project, while supplying the same amount of funds (segment $A B$ along the E-level line). 
Figure 3. Equilibrium Levels of Capital Investment and Repayment Pledge. Case of Repudiation Risk Accruing to Both States.

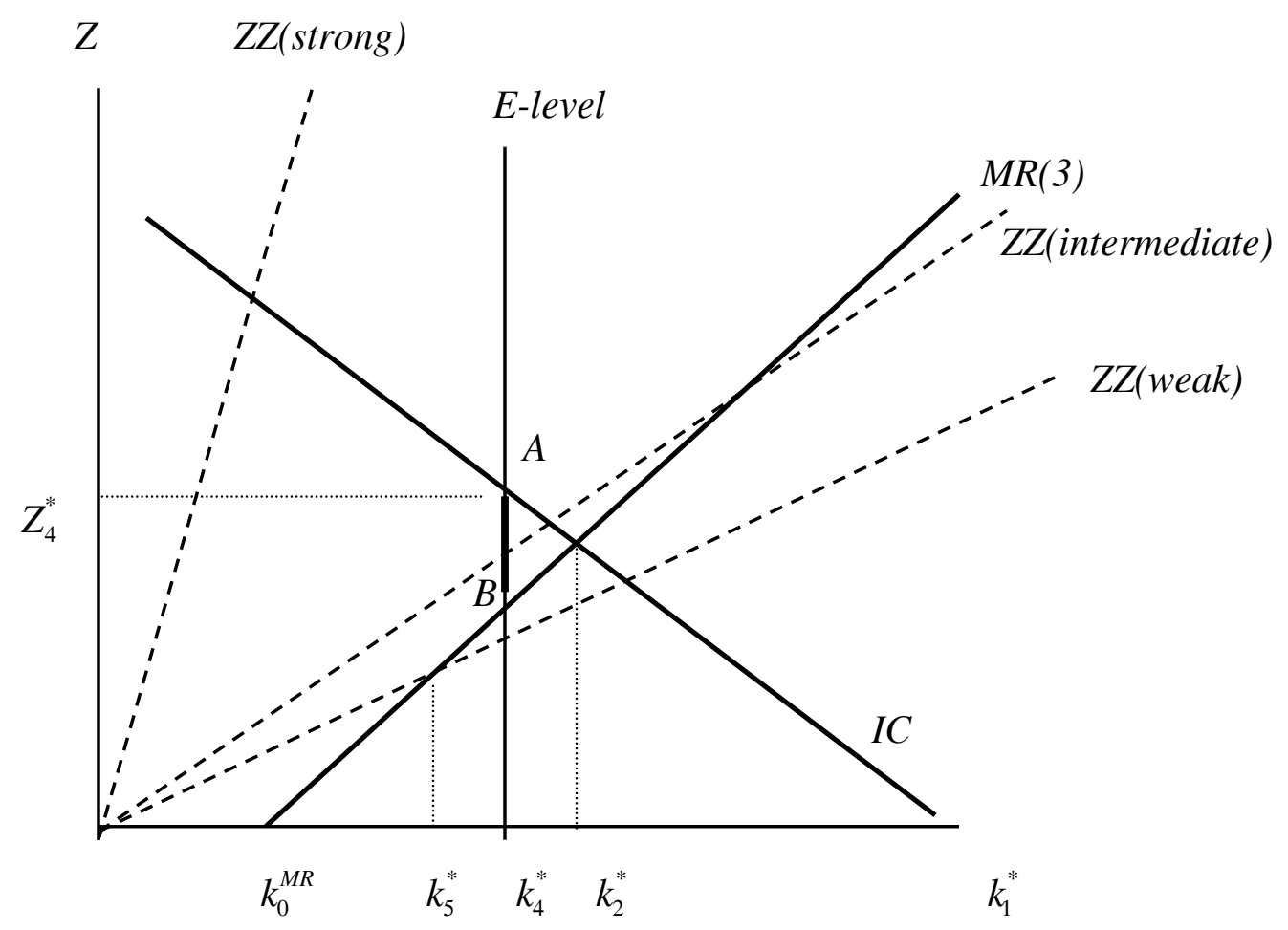

Subsequently, as before in Case 2.1, capital and repayment levels for weaker effect of repudiation risk reduction are given by the following set:

$\left(k_{5}^{*}, Z_{5}^{*}\right) \in\left\{(k, Z) \in R_{+}^{2}: k_{0}^{M R} \leq k<k_{4}^{*} \wedge 0 \leq Z<Z_{4}^{*}\right\} \subset\left\{(k, Z) \in R_{+}^{2}: k_{0}^{M R} \leq k<k_{2}^{*} \wedge 0 \leq Z<Z_{2}^{*}\right\}$

Hence, overall strong link between the repudiation risk and the size of the project allows for the optimal level of investment and repayment pledge to reach the same position as in the case of non-binding repudiation risk in good state of nature. However, with weaker effect of project characteristics on repudiation risk, the level of investment falls at the optimum to $k_{4}^{*}$, while the level of ex ante commitment pledge required to raise this amount rises (possibly even above the case 2.1 levels) to $Z_{4}^{*}$. The distance $A B$ in Figure 3 above therefore represents the risk premium required by the lenders in presence of the repudiation risk binding in both states. 


\section{Conclusions.}

The present study develops a comprehensive model of investments in presence of the investment-contingent repudiation risk and moral hazard. In departure from traditional literature on repudiation risk, the model presented above proposes a link between the size of the project and the level of repudiation risk. We assume that public information and scrutiny that accompany large-scale investment projects act to reduce the risk of repudiation in the model. Using as the foundation the model of Gertler and Rogoff, we treat as a benchmark the case of no repudiation risk. Extending Lane $(1998,1999)$ analysis of the repudiation risk in Gertler and Rogoff model to include consideration of the investment project size effect on repudiation risk, we consider two main cases:

- case 1 corresponding to the situation where project-contingent repudiation risk applies only in the bad state of nature, and

- $\quad$ case 2 where repudiation risk enters both good and bad states of nature.

Comparing the cases outlined above with the benchmark model, we show that in case of repudiation risk applicable to the bad state of nature alone, when marginal benefits of reducing repudiation risk are high, borrowers are able to leverage the potential expropriation funds. Incentives to raid the loan funds fall slower than the ability of borrowers to repay the loan. Hence, lenders are willing to lend more the stronger the effect of capital size on repudiation risk. With weak effect of capital stock on repudiation risk, however, the lenders are not willing to supply capital in excess of the optimal amount determined by the repudiation risk constraint and lender repayment constraint.

Overall, there exist an optimal level of repudiation risk, determined by point at which lenders are willing to supply maximum level of loans in exchange for being reimbursed by the borrowers with the proceeds from investment project. Borrowers will hold zero bonds and will invest all borrowed funds into risky project. They will ex-ante commit to repay exactly the share that can be seized by lenders from the borrowers. Comparing these results with benchmark no repudiation risk case, we have that optimal levels of 
capital investments are lower in presence of repudiation risk. Hence, as expected in presence of effective moral hazard and repudiation risk (at least in one state) we achieve lower capital levels than in case where repudiation risk is effectively non-binding.

The second case covers the environment in which the repudiation risk applies to both states of nature. In this case we show that optimal level of capital investments is lower overall. In case of strong effect of repudiation risk the resulting level of capital expenditure will be below the levels achieved in similar case under the assumption that repudiation risk binds in 'bad' state alone. The result is expected. Relative to the first case where repudiation risk applies in bad state of nature, in the second case investors are concerned with repudiation risk in both states. Such increase in overall uncertainty warrants higher demanded repayment pledge and implies lower capital expenditure. It is important to note that in this case investors are willing to accept lower repayment as repudiation risk is falling while supply the same amount of funds.

However in both cases whenever repudiation risk links to the size of the project outlay of capital are strong, entrepreneurs are able to raise funding at the levels approaching those in the benchmark model.

Thus, overall the model supplies intuitively plausible predictions that a stronger linkage between repudiation risk and investment levels will have a stronger effect on the required rate of return in order to provide incentives for the investors to supply the required capital. Repudiation risk consideration magnifies the overall negative effects of moral hazard. The project-contingent nature of repudiation risk in our case relaxes the overall repudiation risk, since both the lenders and the borrowers are aware of the positive effects of the project size on the level of risk. Thus we can expect that, ceteris paribus, large projects will obtain more readily available financing, while smaller projects will require higher pledge or collateral funding from the entrepreneur in order to secure a loan.

These results lend a natural means to account for the puzzling empirical effects of the limited liability and bankruptcy liquidation clauses mentioned in the introduction. The 
puzzle arises in so far as traditional theoretical models of lending in presence of moral hazard imply the reverse effects of limited liability on the ability of the entrepreneurs to raise credit relative to the size of the projects. In our model large projects are favoured by investors due to the link between the size of the project and the level of the repudiation risk. The smaller (less wealthy) entrepreneurs and projects are less likely to benefit from the repudiation risk linkage. This implies that in so far as limited liability and bankruptcy liquidation clauses have the same effect on lowering the expected ability of entrepreneurs to repay the lenders in case of bad outcome, it is the larger investors who have greater access to the credit markets. Thus our model confirms the empirical regularities observed in the literature.

In so far as the present study offers a way of endogenising the repudiation risk by linking the level of risk with the characteristic of the project itself, the model presented above offers an interesting case for the future empirical analysis.

Firstly, it confirms the general hypothesis that democratic institutions of checks and balances can act in asymmetric fashion on the degree of repudiation risk. With large investment project being subject to the greater scrutiny in local and international media, costs of monitoring the project development and the threat of potential public exposure of the loan raiding entrepreneurs act to ameliorate the repudiation risk and lower the requirements on repayment pledge and collateral.

Secondly, the study develops an explicit relationship between the testable hypotheses concerning the observable environment and the ex ante analysis of the potential investment projects.

Thirdly, we show that the model can be easily interpreted in the context of the force majeur repudiation risk (bad state only case) and the general repudiation risk. Both types can be separated within the constraints of the model and the effects of their differences can be traced back to the ability of the entrepreneurs to raise funds. Of even greater importance is the fact that the size of the project under the assumptions of the democratic 
market-driven institutions, can be intrinsically linked to these differences as well. While force majeur causes may apply to the repudiation raid whereby in the bad state of nature, especially when such bad state is macroeconomic (down cycle, country-wide shock, etc) even in democratic market-oriented societies, the general repudiation risk most certainly meets no approval from the general electorate. Thus the external environment differences between these two forms of repudiation risk must be kept clearly distinguished in any model of investment under uncertainty with the possibility of capital funds expropriation. Our model satisfies this criterion.

\section{Bibliography.}

Berkowitz, J. and M. White (2002) Bankruptcy and Small Firms' Access to Credit NBER Working Paper 9010, July 2002

Gertler, M.(1992) Financial Capacity and Output Fluctuations in an Economy with Multi-period Financial Relationships, Review of Economic Studies, Vol.59.

Gertler, M., Rogoff, K. (1990) North-South Lending and Endogenous Capital Market Inefficiencies, Journal of Monetary Economics, 26 (1990), pages 245-266.

Gropp, R., Scholz, J.K. and M. White (1996) Personal Bankruptcy and Credit Supply and Demand, NBER Working Paper 5653, July 1996

Holmstrom, B. and J. Tirole (1998) Private and Public Supply of Liquidity, Journal of Political Economy, Number 1, Vol. 106, February 1998.

Lane, P. (1998) Evolution of the External Account Under International Capital Market Frictions, Economic Letters, 59 (1998), pages 347-351.

Lane, P. (1999) North-South Lending with Moral Hazard and Repudiation Risk, Review of International Economics, Volume 7, Issue 1, February 1999, pages 50-58. 